\title{
ASSESSMENT OF ANTIMICROBIAL ACTIVITY OF NOVEL DISINFECTANT BASED ON PEROXYGEN/BIGUANIDE/ALCOHOL COMBINATION
}

\author{
Mostafa Essam Eissa*, Mohab Abd El Naby, Ahmed Saber Nouby
}

\begin{abstract}
Dept. of Microbiological and Quality Control, Hikma Pharma Company, $2^{\text {nd }}$ Industrial Zone, $6^{\text {th }}$ of October City, Egypt.
\end{abstract}

Submitted: $13-01-2014$

Revised: 15-03-2014

Accepted: 23-05-2014

*Corresponding author Mostafa Essam Eissa

Email :

Mostafaessameissa

@yahoo.com

\begin{abstract}
A new disinfectant formula based on combination of Hydrogen peroxide $0.6 \mathrm{~g} \%$, Chlorohexidine gluconate $0.5 \mathrm{~g} \%$ and Isopropanol $70.5 \mathrm{~g} \%$ was investigated to be used as broad spectrum disinfectant in an attempt to make better control over microbial bioburden in clean area during critical processes. A proper neutralization method was first implemented using combination of dilution $1: 10(\mathrm{v} / \mathrm{v})$ and chemical inactivation method using LBC3T then disinfectant efficacy study was conducted using surface challenge test and finally compatibility with other disinfectants was performed to ensure that there is no adverse interaction between them. This new product demonstrated more than 3 log reduction (LR) in less than one minute against tested vegetative bacteria and yeast Bacillus subtilis $(>4.68,>4.81$, $>3.85$ and $>4.88$ ), Pseudomonas aeruginosa ( $>4.00,>4.34$, $>3.85$ and $>4.04)$ Candida albicans $(>4.11,>4.18,>4.95$ and $>4.48)$, Micrococcus lylae $(>5.56,>5.56,>5.65$ and 5.74$)$ and Leifsonia aquaticum $(>5.82,5.79,>5.75$ and $>5.74)$ but about $15 \mathrm{~min}$ were needed to achieve high log reduction against Aspergillus niger (3.02, 2.94, 2.91 and 3.10) and no remarkable log reduction of bacterial spores of Bacillus subtilis and Bacillus pumilus even after $30 \mathrm{~min}$ of contact time on coupons inoculated with microorganisms. There is no interaction between this new formula and any other commonly used disinfectants in pharmaceutical facility. The new disinfectant may be used as sanitizer with good activity but not as sporicidal agent for up to $30 \mathrm{~min}$ contact time.
\end{abstract}

Key words: Neutralization method, surface challenge test,compatibility

\section{INTRODUCTION}

There has been a dramatic increase in the usage of chemical disinfectants in pharmaceutical industries (Maillard, 2005). The practice of rotating disinfectants as a means of proactively eradicating a broad spectrum of microorganisms that may be present in a facility is nowadays common practice in the pharmaceutical industry as well as a regulatory expectation. In the "EC Guide to Good Manufacturing Practice, Revision to Annex 1" (EC., 2003), it is stated that "where disinfectants are used, more than one type should be employed". The regulatory expectation is that facilities, systems, equipment, programs, and processes (to include cleaning and disinfection) should be periodically reviewed to confirm that they remain valid and in a state of control (EU., 2001).
The most likely microflora found in pharmaceutical manufacturing can be hard to come by a definite source. The most commonly occurring microorganisms come from human skin (either commensurable or transient) are Gram-positive microorganisms and common environmental fungi which include the following: Staphylococcus aureus, Micrococcus species, Bacillus species, Candida species, Aspergillus niger. Whereas those associated with eyes, ears and mucus include Gram-negative microorganisms, which can arise on rare occasions directly from the operator and include Psendeomonas aeruginosa (Jiminez, 2004). Strains of Staphylococcus aureus, Escherichia coli, Proteus vulgaris, Serratia marcescens and Pseudomonas aeruginosa were isolated from pharmaceutical effluent water (Lateef, 2004). 
Candida albicans as the most important nosocomial fungal pathogen can survive up to 4 months on surfaces that many gram-negative species, such as Acinetobacter species, Escherichia coli, Klebsiella species, Pseudomonas aeruginosa, Serratia marcescens and Shigella species, can also survive for months (Kramer et al., 2006). Predominant contaminant bacteria in the clean rooms air of pharmaceutical facility were a group of Gram-positive bacteria: either sporeforming Bacillus species, or non-sporulating Staphylococcus species and Microbacterium species (Wu and Liu, 2007).

All chemical agents have their limitations either in terms of their antimicrobial activity, resistance to organic matter, stability, incompatibility, irritancy, toxicity or corrosivity. To overcome the limitations of an individual agent, formulations consisting of combinations of agents are available. For example, ethanol has been combined with chlorhexidine to produce more active preparations. Compounds containing the biguanide structure could be expected to have good antibacterial and antifungal effect. The germicidal properties of hydrogen peroxide have been known for more than a century, but use of low concentrations of unstable solutions did little for its reputation. However, stabilized solutions are now available and due to its unusual properties and antimicrobial activity, hydrogen peroxide has a valuable role for specific applications. The aliphatic alcohols, notably isopropanol, which are used for disinfection and antisepsis, are bactericidal against vegetative forms. They possess properties such as a cleansing action and volatility, are able to achieve a rapid and large reduction in flora (Hugo and Russell, 1998).

Shaker et al., 1986 showed that many disinfectants are bactericidal or bacteristatic at low concentrations for non-sporulating bacteria, including the vegetative cells of Bacillus species, but high concentrations may be necessary to achieve a sporicidal effect. By contrast, even high concentrations of alcohol, phenolics, QACs, and chlorhexidine lack a sporicidal effect. In one form of intrinsic resistance study in fungi, the available information links cell wall glucan, wall thickness, and relative porosity to the susceptibility of Saccharomyces cerevisiae to chlorhexidine (Hiom et al., 1992; Hiom et al., 1996). Demple, 1991 described a resistance in bacteria to peroxygens by mopping up free radicals.

Our concern is focused on disinfectant qualification studies performed on new disinfectant formula so that it can reduce bioburden on inanimate surfaces in reasonable time, to examine the benefit of this synergistic combination and to study possible adverse interaction with other disinfectants currently in use. It must meet the acceptance criteria of microbial cleanliness stated by guidelines. As well as it should be tested for its true spectrum against different types and forms of microorganisms to verify the efficacy of the combination. Some literatures have used terms of "disinfectant" and "biocide" synonymously. However, we will use here only one term "disinfectant" as "biocide" is more general term that includes several categories and classes of chemical compounds that are not intended for control of bacterial and fungal contamination.

\section{MATERIAL AND METHODS Preparation of test microorganisms}

Identification of microbial isolates was done using miniaturized biochemical kits using BBL CRYSTAL ID kits as that stated by Ashour et al., 2011. Microbial suspensions were prepared using seed-lot culture technique according to method described by Eissa and Mahmoud, 2012 and Eissa et al., 2013. Representative organisms to each microbial category were selected to be used in this study as they are commonly found in the environment of pharmaceutical facility either in clean area and/or water system (Table I).

\section{Disinfectant qualification study}

All tests were done in triplicates. Neutralizer evaluation test was performed as Eissa et al., 2012 by preparing 3 groups: viability $(\mathrm{V})$, neutralizer (N), neutralizer-disinfectant (D) populations and two comparison criteria namely Neutralizer toxicity $(\mathrm{NT})=\mathrm{N} / \mathrm{V}$ and Neutralizer efficacy $(\mathrm{NE})=\mathrm{D} / \mathrm{N}$. Both neutralizing broths: Fluid Thioglycollate Medium (FTM) and LBC3T were prepared and autoclaved as an ordinary culture media (Table II) . 
Table I. Microorganisms used in the current study, their origins and forms.

\begin{tabular}{|c|c|c|}
\hline Microorganism & ATCC(a) & Form \\
\hline Bacillus subtilis & 6633 & Bacterial spore and Vegetative gram-positive bacilli \\
\hline Bacillus pumilus & 14884 & Bacterial spore \\
\hline Aspergillus niger & 16404 & Fungal spore \\
\hline Pseudomonas aeruginosa & 9027 & Vegetative gram-negative bacilli \\
\hline Candida albicans & 10231 & Vegetative yeast \\
\hline Micrococcus lylae & EM isolate(b) & Vegetative gram-positive cocci \\
\hline Leifsonia aquaticum & EM isolate $^{(b)}$ & Vegetative gram-positive bacilli \\
\hline
\end{tabular}

(a)=American type of culture collection; (b)=Identified using BBL CRYSTAL ID kits for Gram-positive microorganisms.

Table II Composition of LBC3T and FTM neutralizing broth and their final concentrations as listed in $\mathrm{g} / \mathrm{L}$.

\begin{tabular}{lcc}
\hline Ingredient & LBC3T & FTM \\
\hline Agar & 1.5 & 0.75 \\
Cystine & 1.0 & 0.50 \\
Dextrose & 11.0 & 6.50 \\
Lecithin & 7.0 & \\
Polysorbate 80 & 5.0 & \\
Sodium bisulfite & 2.5 & 2.50 \\
Sodium chloride & 5.0 & 0.50 \\
Sodium thioglycollate & 1.0 & \\
Sodium thiosulfate & 6.0 & 15.00 \\
Tryptone & 30.0 & 5.00 \\
Yeast extract & 10.0 & \\
\hline
\end{tabular}

Disinfectant surface challenge test was done according to Eissa et al., 2014 in triplicates. The test was based on inoculating coupon surface material with $10^{5}$ to $10^{6} \mathrm{CFU}$ approximately then applying disinfectant at different contact times. The tested active disinfectant formula denoted by (A) was Chlorhexidine digluconate $0.5 \mathrm{~g}$, Isopropanol $70.5 \mathrm{~g}$, Hydrogen peroxide $0.6 \mathrm{~g}$ in $100 \mathrm{~mL}$. The disinfectant was used directly as it is without prior special preparation or dilution. Storage was in well closed tight container protected from light in amber glass bottle at room temperature and $\mathrm{RH} \%$ 40-60.

\section{Compatability with other disinfectants in the facility}

A similar method to that of Szybalski and Bryson was done but with modification to fulfill our requirements for testing that can detect if there is antagonism between disinfectants or not. The study was conducted with Ethanol 70\%, Isopropanol 70\%, Tego $20001 \%$ and commercially used sporicidal agent in the facility composed of mixture of 2 peroxygen compounds (Hydrogen peroxide $0.54 \%+$ Peracetic acid 0.09\%) (Szybalski and Bryson, 1952). Test was based on two strips of filter papers impregnated with disinfectants under study in (T) shaped arrangement on solid agar surface inoculated with microbial suspendsion when it was molten. Incubation then observing increase or decrease of the zone of growth inhibition at the intersect of two strips.

\section{Acceptance criteria}

NT and NE ratios were derived utilizing the geometric mean of the recovery in the different populations. Acceptable NT and NE ratios are defined as $\geq 0.75$ (Sutton et al., 2002). Disinfectant is considered effective as antimicrobial if the inoculum is reduced by at 
least $2 \operatorname{logs}$ for bacterial spores and $3 \operatorname{logs}$ for vegetative bacteria and fungi on sample surface coupon (USP, 2014). If there is more than $50 \%$ $(0.3 \mathrm{Log})$ variation of the microbial count result obtained after certain time of contact with disinfectant from the initial control value then there is significant difference and the disinfectant exerts its effect. This criterion was taken to account for normal plating variability. This will help to detect slight changes not great in magnitude (i.e. not in level of 2 to $3 \log _{10}$ reduction) (Clontz, 2008). No adverse antagonistic interaction between disinfectant under study and other disinfectants if there is any reduction in the Inhibition Zone (IZ) at the intersection region of the 2 strips if compared with that of the ends around the edges of each strip (Szybalski and Bryson, 1952). All statistical analysis was performed using t-test and ANOVA using GraphPad Prism version 5.00 for Windows.

\section{RESULTS AND DISCUSSION}

Both FTM and LBC3T neutralizers had passed NT when inoculated with the index microorganisms used in this study with recovery ratio $\geq 0.75$ (Table III). The possible nutritive value of neutralizing broth to some microorganisms (FTM to B.subtilis) is needed to be investigated especially, for those showing significantly higher results than control group. In NE study LBC3T was able to recover all microorganisms in contrast to FTM which recovered fungi only so further tests was discontinued with the 2 environmental isolates (EM) bacteria. LBC3T was generally accepted as neutralizer for disinfectant qualification study (Table IV). Similarly, the possible impact of chemical neutralization and its reaction products positively on microbial recovery must be subjected to further study to find the mechanism behind the significantly higher recovery percent of Pseudomonas aeruginosa and Micrococcus bylae from LBC3T-Disinfectant combination.

The new disinfectant reduced microbial vegetative count effectively after $1 \mathrm{~min}$ yet it did not affect bacterial spores while it showed significant decline in fungal spore count after $5 \mathrm{~min}$ contact and passed the test after $15 \mathrm{~min}$ and practically no recovery was observed after $30 \mathrm{~min}$ contact. According to these results tested microorganisms could be arranged based on sensitivity to the disinfectant in the following descending order: Vegetative bacteria and yeast (B.subtilis, P.aeruginosa, C.albicans, M. Lylae and L.aquaticum), mold spore (A.niger) and bacterial spores (B.subtilis and B.pumilus) (Table V).

The disinfectant did not have deleterious effect upon contact with materials under study and no antagonistic reaction was observed with any other commonly used disinfectants. Representative microorganisms of each type were selected in this test (Gram positive, Gram negative, bacterial spore and fungi) to demonstrate results in figure (1). Results of disinfectant compatibility study revealed two interesting findings. Firstly, the zone of inhibition around new formula strip is greater than that of Isopropanol and Ethanol 70\% alone and other commercial disinfectants indicating that synergistic combination exists between alcohol and the other two constituents especially, for Bacillus species. Secondly, the results of both B.subtilis and C.albicans from disinfectant validation study gave reverse outcome from the zone of inhibition data in compatibility study this finding needs more investigation. However, the suggested reasons for this result may be: possible impact of agar media composition and $\mathrm{pH}$ on the diffusion and the activity of disinfectant compounds and/or concentration exponent played a role in disinfectant activity as it get diluted during diffusion and thus, affecting the potency of the synergistic combination along with MIC of each microorganism to determine the zone size. Bacillus spp. wide zone of inhibition indicated inhibition of germination of the spores and their killing may not be necessarily accomplished but if significant eradication of spores did occur this may be due to prolonged contact time which is measured in hours not in minutes as in disinfectant qualification study. C.albicans, on the other hand, showed small zone of inhibition which gave an indication that the activity of this formula had fallen shortly after small diffusion through agar with regard to this yeast's MIC. 
Table III Neutralizer toxicity screening study for used disinfectants against index microorganisms.

\begin{tabular}{|c|c|c|c|c|}
\hline Microorganism & Neutralizer & Test (CFU) ${ }^{(\mathrm{f})}$ & Control (CFU) ${ }^{(\mathrm{f})}$ & Recovery \%(g) \\
\hline \multirow{2}{*}{$\begin{array}{l}\text { Bacillus subtilis } \\
\text { (spore)(d) }\end{array}$} & LBC3T(b) & $34( \pm 3.19)$ & $42( \pm 3.85)$ & $81( \pm 7.60)$ \\
\hline & $\operatorname{FTM}^{(c)}$ & $83( \pm 7.42)$ & $87( \pm 8.65)$ & $95( \pm 8.53)$ \\
\hline \multirow{2}{*}{$\begin{array}{l}\text { Bacillus pumilus } \\
\text { (spore)(d) }^{(\mathrm{d})}\end{array}$} & LBC3T(b) & $96( \pm 9.16)$ & $82( \pm 6.98)$ & $117( \pm 11.17)$ \\
\hline & $\mathrm{FTM}^{(\mathrm{c})}$ & $60( \pm 5.27)$ & $80( \pm 3.13)$ & $75( \pm 6.59)$ \\
\hline \multirow{2}{*}{$\begin{array}{l}\text { Aspergillus niger } \\
\text { (spore)(e) }\end{array}$} & LBC3T(b) & $49( \pm 4.45)$ & $44( \pm 4.38)$ & $111( \pm 10.11)$ \\
\hline & $\mathrm{FTM}^{(\mathrm{c})}$ & $53( \pm 4.90)$ & $49( \pm 4.20)$ & $108( \pm 10.00)$ \\
\hline \multirow{2}{*}{ Bacillus subtilis } & LBC3T(b) & $55( \pm 5.47)$ & $55( \pm 2.31)$ & $100( \pm 9.95)$ \\
\hline & $\operatorname{FTM}^{(c)}$ & $68( \pm 6.77)$ & $50( \pm 4.85)$ & $136( \pm 13.54)$ \\
\hline \multirow{2}{*}{$\begin{array}{l}\text { Pseudomonas } \\
\text { aeruginosa }^{(\mathrm{d})}\end{array}$} & LBC3T(b) & $90( \pm 8.89)$ & $83( \pm 8.09)$ & $108( \pm 10.71)$ \\
\hline & $\operatorname{FTM}^{(c)}$ & $107( \pm 10.06)$ & $96( \pm 9.53)$ & $111( \pm 10.48)$ \\
\hline \multirow{2}{*}{ Candida albicans $\mathrm{e}^{\mathrm{e}}$} & LBC3T(b) & $71( \pm 7.03)$ & $90( \pm 8.09)$ & $79( \pm 7.81)$ \\
\hline & $\mathrm{FTM}^{(\mathrm{c})}$ & $42( \pm 3.90)$ & $56( \pm 5.55)$ & $75( \pm 6.96)$ \\
\hline \multirow{2}{*}{ Micrococcus lylae(d) } & LBC3T(b) & $88( \pm 8.70)$ & $85( \pm 4.49)$ & $104( \pm 10.24)$ \\
\hline & $\operatorname{FTM}^{(c)}$ & $50( \pm 4.46)$ & $50( \pm 4.32)$ & $100( \pm 8.92)$ \\
\hline Leifsonia & LBC3T(b) & $92( \pm 9.10)$ & $78( \pm 7.00)$ & $118( \pm 11.67)$ \\
\hline aquaticum $^{(\mathrm{d})}$ & $\mathrm{FTM}^{(\mathrm{c})}$ & $\mathrm{ND}^{(\mathrm{a})}$ & $\mathrm{ND}^{(\mathrm{a})}$ & $\mathrm{ND}^{(\mathrm{a})}$ \\
\hline
\end{tabular}

(a):Not determined as failure of FTM in NE study discourage its use based on the results of other bacteria; (b): New neutralizer formula based on: Lecithin, Bisulfite, L-Cystine, Tween 80, Thiosulfate and Thioglycollate; (c)= Fluid Thioglycollate Medium; (d): Bacterial control and test plates were incubated in 30$35^{\circ} \mathrm{C}$ for 2 to 3 days; (e): Fungal control and test plates were incubated in $20-25^{\circ} \mathrm{C}$ for 3 to 5 days; (f): Average mean (CFU) ( \pm Standard Error); $(\mathrm{g})$ : Average recovery percent $( \pm$ Standard Error of the Percentage).

The neutralizer toxicity is an important consideration as growth inhibition introduced by the intended neutralizer will affect the recovery of microorganisms. Similarly, if only the efficacy of the neutralizer is measured, little is learned by a failure in the study. This failure could be due either to inadequate neutralization, or due to toxicity of the neutralizer confounding the results of the study (Sutton et al., 2002).

In order to obtain accurate data from neutralization study one must take cautions to the inoculums of each organism incorporated in the study. The US Food and Drug Administration Bacterial Analytical Manual (BAM) recommends 25-250 CFU/plate as a countable range (Maturin and Peeler, 2011). We have selected $30 \mathrm{CFU} /$ plate as minimum limit of count as error factor increases exponentially and above $300 \mathrm{CFU}$ crowdness effect increases counting error. In neutralizer evaluation study
$100 \mathrm{CFU}$ maximum count was chosen to challenge test sensitivity. However it should be remembered that this limit is for bacteria and yeast while molds have $80 \mathrm{CFU}$ as maximum count/plate.

The acceptance criterion of 0.75 was used in the presumptive test for both the NT and the NE comparisons (Sutton et al., 2002). An alternate acceptance criterion of 0.5 (50\% recovery) was considered as this has been suggested as a suitable criteria (USP, 1999), but this was rejected as too permissive. Expansion of the acceptance range from 0.74 to 0.50 would have included an additional 2 comparisons in case of FTM namely Aspergillus niger and Pseudomonas aeruginosa.

NT study performed for both LBC3T and FTM neutralizers revealed that they passed the test and they were not different significantly from each other hence they do not adversely affect the recovery of tested microorganisms. 
Table IV Neutralizer efficiency screening study for new disinfectant against index microorganisms using 2 chemical neutralizers.

\begin{tabular}{|c|c|c|c|c|}
\hline Recovery \%(g) & Control (CFU) ${ }^{(a, f)}$ & Test (CFU) ${ }^{(a, f)}$ & Neutralizer & Microorganism \\
\hline $94( \pm 9.18)$ & $34( \pm 3.30)$ & $32( \pm 3.12)$ & LBC3T(b) & \multirow{2}{*}{$\begin{array}{r}\text { Bacillus subtilis } \\
\text { (spore)(d) }^{(\mathrm{d})}\end{array}$} \\
\hline 0 & $100( \pm 8.00)$ & 0 & FTM(c) $^{(c)}$ & \\
\hline $93( \pm 9.26)$ & $96( \pm 9.54)$ & $89( \pm 8.89)$ & LBC3T (b) & \multirow{2}{*}{$\begin{array}{r}\text { Bacillus pumilus } \\
\text { (spore) }\end{array}$} \\
\hline 0 & $89( \pm 7.76)$ & 0 & FTM $^{(c)}$ & \\
\hline $86( \pm 8.37)$ & $49( \pm 4.23)$ & $42( \pm 4.10)$ & LBC3T (b) & \multirow{2}{*}{$\begin{array}{r}\text { Aspergillus niger } \\
\text { (spore) })^{(\mathrm{e})}\end{array}$} \\
\hline $53( \pm 3.70)$ & $30( \pm 2.22)$ & $16( \pm 1.11)$ & $\mathrm{FTM}^{(\mathrm{c})}$ & \\
\hline $93( \pm 8.64)$ & $55( \pm 5.09)$ & $51( \pm 4.75)$ & $\mathrm{LBC}^{3} \mathrm{~T}^{(\mathrm{b})}$ & \multirow{2}{*}{ Bacillus subtilis } \\
\hline 0 & $32( \pm 1.91)$ & 0 & FTM $^{(c)}$ & \\
\hline $137( \pm 13.61)$ & $71( \pm 7.01)$ & $97( \pm 9.66)$ & LBC3T (b) & \multirow{2}{*}{$\begin{array}{l}\text { Pseudomonas } \\
\text { aeruginosa(d) }\end{array}$} \\
\hline $53( \pm 3.76)$ & $66( \pm 6.00)$ & $35( \pm 2.48)$ & FTM $^{(c)}$ & \\
\hline $103( \pm 10.3)$ & $90( \pm 8.85)$ & $93( \pm 9.27)$ & LBC3T (b) & \multirow{2}{*}{ Candida albicans ${ }^{(\mathrm{e})}$} \\
\hline $88( \pm 8.20)$ & $56( \pm 5.38)$ & $49( \pm 4.59)$ & $\mathrm{FTM}^{(\mathrm{c})}$ & \\
\hline $139( \pm 13.73)$ & $88( \pm 8.70)$ & $122( \pm 12.08)$ & LBC3T (b) & \multirow{2}{*}{ Micrococcus lylae (d, h) } \\
\hline $\mathrm{ND}^{(\mathrm{i})}$ & $\mathrm{ND}^{(\mathrm{i})}$ & $\mathrm{ND}^{(\mathrm{i})}$ & $\mathrm{FTM}^{(\mathrm{c})}$ & \\
\hline $107( \pm 10.49)$ & $92( \pm 9.17)$ & $98( \pm 9.65)$ & LBC3T (b) & \multirow{2}{*}{ Leifsonia aquaticum $^{(\mathrm{d}, \mathrm{h})}$} \\
\hline $\mathrm{ND}^{(\mathrm{i})}$ & $\mathrm{ND}^{(\mathrm{i})}$ & $\mathrm{ND}^{(\mathrm{i})}$ & FTM $^{(c)}$ & \\
\hline
\end{tabular}

(a): Disinfectant mixed with neutralizing diluent as test and neutralizing diluents minus disinfectant as control; (b): New neutralizer formula based on: Lecithin, Bisulfite, L-Cystine, Tween 80, Thiosulfate and Thioglycollate; (c)= Fluid Thiogllycolate Medium; (d): Bacterial control and test plates were incubated in 30$35^{\circ} \mathrm{C}$ for 2 to 3 days; (e): Fungal control and test plates were incubated in $20-25^{\circ} \mathrm{C}$ for 3 to 5 days; (f): Average mean (CFU) ( \pm Standard Error); (g): Average recovery percent $( \pm$ Standard Error of the Percentage); (h): Environmental isolates identified by miniaturized biochemical system; (i): Not determined after failure of preliminary neutralization study for standard strains using FTM which discourage its use based on the results of other bacteria.

The other important subsequent aspect is $\mathrm{NE}$ test using FTM or LBC3T as primary neutralizer and while the first one failed with all microorganisms the second one was on the other hand successful with them all. Sutton $e t$ al., 2002 found that Dey-Engly Broth (DEB) and NIH thiogllycolate (close in composition to FTM) were non toxic against microorganisms but NIH thiogllycolate could not effectively recover some of them from disinfectants under study while DEB was more successful. The reason behind that is DEB (similar to LBC3T) possesses greater neutralization capacity due to its ingredients. FTM neutralizing broth components are actually presenting small part of LBC3T neutralizing broth.
Surface-active agents, notably non-ionic agents, can affect the activity of antimicrobial compounds. Many non-ionic surfactants are used as neutralizing agents (Maillard, 2005). Tween 80 is one the component of LBC3T. The antimicrobial properties of aliphatic alcohol such as Isopropanol $70 \%$ could be diminished by dilution because as it -as stated in USP Chapter <1072> Disinfectants and Antiseptics- has high concentration exponent $(\eta)(6.0-12.7)$ while that of Chlorohexidine is 2.0 so dilution may be of little value and chemical neutralization using Tween 80 and Lecithin such that in LBC3T is the best approach. 
Table V Disinfectant validation study of new disinfectant against index microorganisms on different surface samples at different time intervals.

\begin{tabular}{|c|c|c|c|c|c|}
\hline $\begin{array}{c}\text { Stainless steel } \\
(316 \mathrm{~L})^{(\mathrm{d})}\end{array}$ & $\begin{array}{c}\begin{array}{c}\text { Curtain } \\
\text { (PVC) }\end{array} \\
\text { LR }^{(\mathrm{c})}\end{array}$ & $\begin{array}{c}\begin{array}{c}\text { Floor } \\
(\text { Vinyl)(d) }\end{array} \\
\text { LR(c) }^{(\mathrm{c})}\end{array}$ & $\begin{array}{c}\text { Wall (ECG) } \\
(\mathrm{b}, \mathrm{d})\end{array}$ & Microorganism(a) $^{(a)}$ & 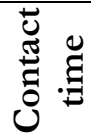 \\
\hline $0.30( \pm 0.027)$ & $0.17( \pm 0.016)$ & $0.20( \pm 0.019)$ & $0.29( \pm 0.028)$ & Bacillus subtilis (spore) & \\
\hline $0.14( \pm 0.010)$ & $0.26( \pm 0.025)$ & $0.03( \pm 0.002)$ & $0.14( \pm 0.013)$ & Bacillus pumilus (spore) & \\
\hline $0.16( \pm 0.011)$ & $0.00( \pm 0.001)$ & $0.50( \pm 0.047)$ & $0.43( \pm 0.040)$ & Aspergillus niger (spore) & \\
\hline$>4.88$ & $>4.87$ & $>4.81$ & $>4.68$ & Bacillus subtilis & \\
\hline$>4.04$ & $>3.85$ & $>4.34$ & $>4.00$ & Pseudomonas aeruginosa & \\
\hline$>4.48$ & $>4.95$ & $>4.18$ & $>4.11$ & Candida albicans & \\
\hline$>5.74$ & $>5.65$ & $>5.56$ & $>5.56$ & Micrococcus lylae & \\
\hline$>5.74$ & $>5.75$ & $>5.79$ & $>5.82$ & Leifsonia aquaticum & \\
\hline $0.00( \pm 0.001)$ & $0.03( \pm 0.001)$ & $-0.15( \pm 0.014)$ & $0.00( \pm 0.0028)$ & Bacillus subtilis (spore) & \\
\hline$-0.07( \pm 0.006)$ & $0.08( \pm 0.007)$ & $-0.08( \pm 0.006)$ & $0.04( \pm 0.003)$ & Bacillus pumilus (spore) & \\
\hline $0.99( \pm 0.095)$ & $1.03( \pm 0.101)$ & $0.81( \pm 0.080)$ & $1.07( \pm 0.100)$ & Aspergillus niger (spore) & \\
\hline$>5.97$ & $>5.85$ & $>5.04$ & $>5.48$ & Bacillus subtilis & \\
\hline$>4.04$ & $>3.85$ & $>4.34$ & $>4.00$ & Pseudomonas aeruginosa & \\
\hline$>4.48$ & $>4.95$ & $>4.18$ & $>4.11$ & Candida albicans & \\
\hline$>5.74$ & $>5.65$ & $>5.56$ & $>5.56$ & Micrococcus lylae & \\
\hline$>5.74$ & $>5.75$ & $>5.79$ & $>5.82$ & Leifsonia aquaticum & \\
\hline$-0.10( \pm 0.006)$ & $0.07( \pm 0.004)$ & $0.00( \pm 0.001)$ & $0.05( \pm 0.003)$ & Bacillus subtilis (spore) & \\
\hline $0.02( \pm 0.001)$ & $0.03( \pm 0.002)$ & $0.01( \pm 0.001)$ & $0.03( \pm 0.002)$ & Bacillus pumilus (spore) & \\
\hline $3.10( \pm 0.307)$ & $2.91( \pm 0.231)$ & $2.94( \pm 0.255)$ & $3.02( \pm 0.299)$ & Aspergillus niger (spore) & \\
\hline$-0.03( \pm 0.002)$ & $0.04( \pm 0.003)$ & $0.31( \pm 0.029)$ & $0.00( \pm 0.001)$ & Bacillus subtilis (spore) & \\
\hline $0.03( \pm 0.002)$ & $0.08( \pm 0.005)$ & $-0.26( \pm 0.024)$ & $0.04( \pm 0.003)$ & Bacillus pumilus (spore) & \\
\hline$>5.94$ & $>5.58$ & $>5.84$ & $>5.56$ & Aspergillus niger (spore) & \\
\hline
\end{tabular}

(a): Initial inoculums size per coupon of B.subtilis (spore), B.pumilus (spore), A.niger (spore), B.subtilis, P.aeruginosa, C.albicans, M.lylae and L.aquaticum were $6.6 \times 10^{5}, 4.4 \times 10^{5}, 1.0 \times 10^{6}, 1.0 \times 10^{6}, 1.0 \times 10^{5}, 1.0 \times 10^{5}, 1.0 \times 10^{6}$ and 1.0x106 CFU respectively; (b): Epoxy-coated gypsum; (c): Logarithmic reduction of microbial bioburden from baseline inoculum (control count not subjected to the effect of disinfectant) recovered from the test surfaces; (d): Average log reduction ( \pm Standard Error).

Both DEB and LBC3T have close compostion from each other. Sodium thiosulfate interacts with Hydrogen peroxide to stop its action thus chemical neutralization is the effective while dilution is not effective because $\eta$ of Hydrogen peroxide is 0.5 .

The overall kinetic of microbial death was obvious with A.niger where initial shoulder of slow rate of death was observed followed by greater rate of kill. The final part of the sigmoid curve was not seen may be due very low number of mold which was not detected or may be found between 15 and $30 \mathrm{~min}$. Spores of genus Bacilli were obviously found to be not affected within $30 \mathrm{~min}$ contact and the count did not change to any significant extent. On contrary yeast and vegetative bacterial cells were found to be killed very quickly within $1 \mathrm{~min}$ so that the curve observed with the mold could not be detected with those organisms. 
New disinfectant formula interaction with other disinfectants

Hydrogen peroxide
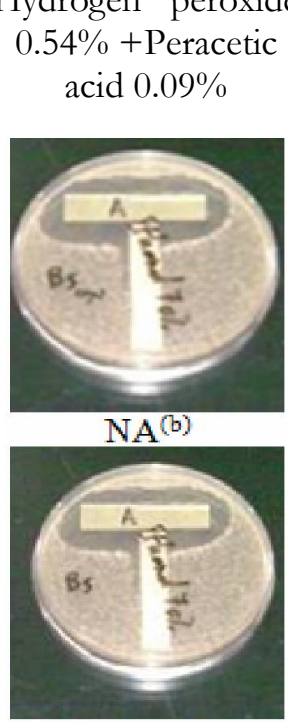

$$
\mathrm{NA}^{(\mathrm{b})}
$$

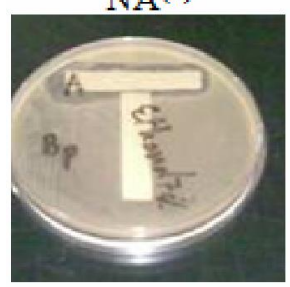

$N A^{(b)}$

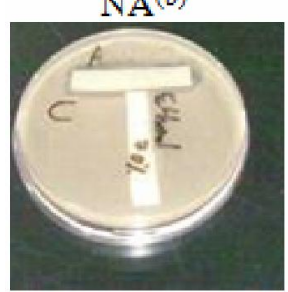

$\mathrm{NA}^{(b)}$

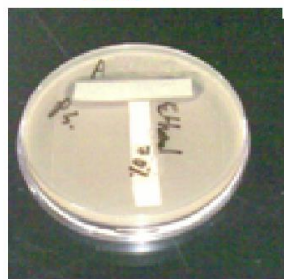

$\mathrm{NA}^{(\mathrm{b})}$
Tego 2000

$1 \%$

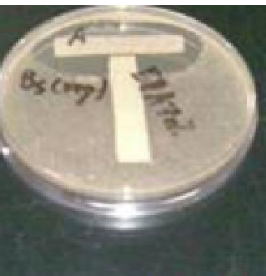

$\mathrm{NA}^{(\mathrm{b})}$

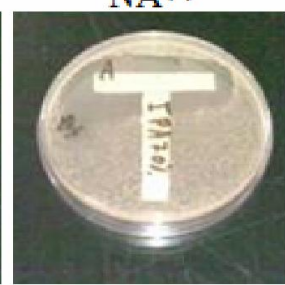

$\mathrm{NA}^{(\mathrm{b})}$

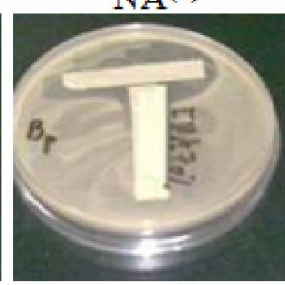

$\mathrm{NA}^{(\mathrm{b})}$

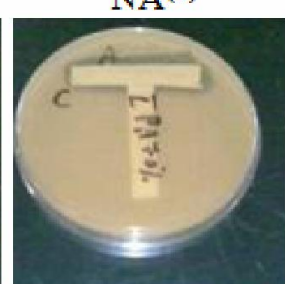

$\mathrm{NA}^{(\mathrm{b})}$

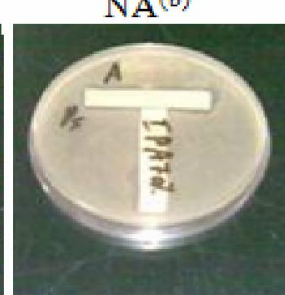

$\mathrm{NA}^{(\mathrm{b})}$
Isopropanol $70 \%$

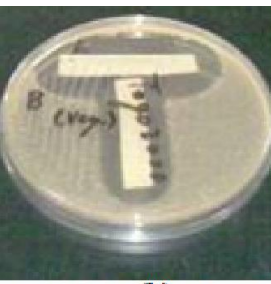

$\mathrm{NA}^{(\mathrm{b})}$

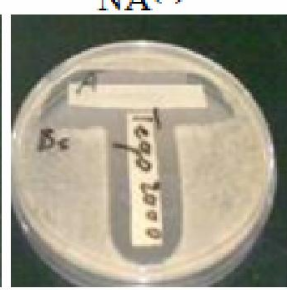

$\mathrm{NA}^{(\mathrm{b})}$

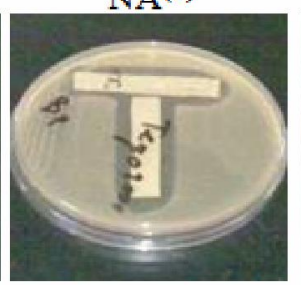

$N A^{(b)}$

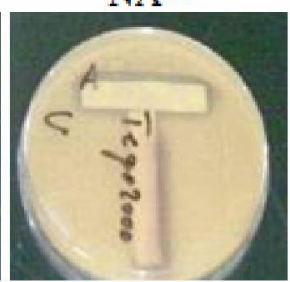

$\mathrm{NA}^{(\mathrm{b})}$

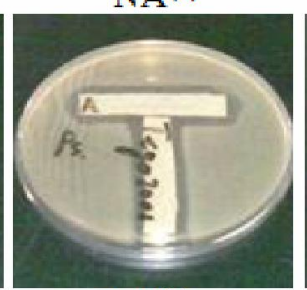

$\mathrm{NA}^{(\mathrm{b})}$
Ethanol 70\%

Organism

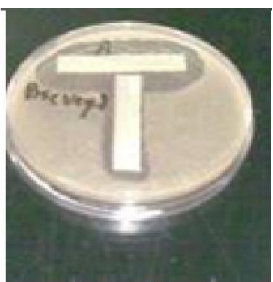

$\mathrm{NA}^{(\mathrm{b})}$

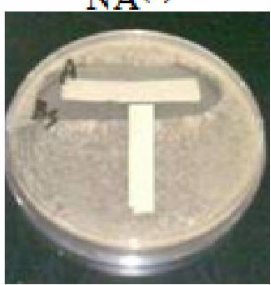

$\mathrm{NA}^{(\mathrm{b})}$

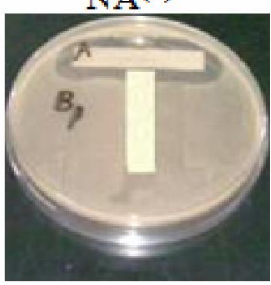

$\mathrm{NA}^{(\mathrm{b})}$

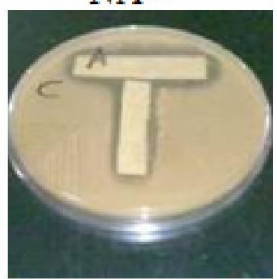

$\mathrm{NA}^{(\mathrm{b})}$

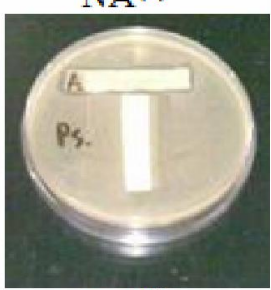

$\mathrm{NA}^{(\mathrm{b})}$
Bacillus Subtilis

(vegetative)

Bacillus subtilis

(spore)

Bacillus Pumilus

(spore)

Candida albicans

\section{Pseudomonas}

aeruginosa

Figure 1. Compatibility study performed for new disinfectant against other disinfectants.

(b) = No antagonism (i.e. no decrease in the zone of inhibition)

$\mathrm{H}_{2} \mathrm{O}_{2}$, probably denatures proteins and enzymes and increases cell wall permeability by disrupting sulfhydryl (-SH) and sulfur (S-S) bonds in addition Ribosomes are possible target site (Block, 1991 and Clontz, 2008). Alcohol and Chlorohexidine act by disrupting membrane permeability in addition to coagulation of proteins and enzymes by chlorohexidine (Clontz, 2008).

Hydrogen peroxide is a widely used disinfectant for disinfection $\mathrm{H}_{2} \mathrm{O}_{2}$ demonstrates broad-spectrum efficacy against viruses, 
bacteria, yeasts, and bacterial spores (Block, 1991). The presence of catalase or other peroxidases in these organisms can increase tolerance in the presence of lower concentrations. Higher concentrations of $\mathrm{H}_{2} \mathrm{O}_{2}$ and longer contact times are required for sporicidal activity (Russel, 1991). With regard to the concentration of Hydrogen peroxide used in this formula $(0.6 \mathrm{gm} \mathrm{\%})$, it could be concluded that its sporicidal effect against Bacillus spores is ineffective during 30 minutes exposure time.

Unlike bacterial spores, fungal spores are part of the normal life cycle of fungi, and, therefore, they are less resistant to chemicals and adverse environmental conditions (Clontz, 2008). This property made A.niger spores more sensitive to the novel disinfectant than bacterial spores- where sporulation is a way of survival against harsh environmental conditions- but normally more resistant than vegetative bacteria and yeast. The roles of the coat(s) and cortex are all relevant to the mechanism(s) of resistance presented by bacterial spores to antiseptics and disinfectants (Foster, 1994). The cell wall of staphylococci and vegetative Bacillus spp. is composed essentially of peptidoglycan and teichoic acid. Neither of these appears to act as an effective barrier to the entry of disinfectants. Since high molecular weight substances can readily traverse the cell wall, this may explain the sensitivity of these organisms to many antibacterial agents (Russell and Russell, 1995). Low-molecular-weight hydrophilic molecules readily pass via the porins into gram-negative cells, but hydrophobic molecules diffuse across the outer membrane bilayer (Russell and Furr, 1986). All disinfectant ingredients are of low molecular weights thus faster penetration could be achieved which gave immediate effect on Gram-negative organism as P.aeruginosa. Yeasts resistance to disinfectants on the other hand is linked to the cell wall porosity, thickness and/or the degree of cross linking (Hiom et al., 1996). Disinfectant formula results on C.albicans showed that it was very sensitive to this combination and the cell wall did not present true barrier for this synergistic combination. A.niger spore surface is hydrophobic and spores tend to aggregate so the initial contact of disinfectant to the surface and the penetration to the interior of the aggregates may take time till achieving penetration and inactivation of the spore. Further investigation is needed to study the mechanism by which the response of fungal spore to disinfectant was delayed.

The size of the inoculum is important for quantitative methods that need to demonstrate a reduction in cell number. In this case, the original inoculums must be high enough to demonstrate the required reduction in number, taking into consideration dilutions caused, for example, by a neutralization step. However, a large inoculum might not necessarily be representative of microbial contamination in practice, and might cause an 'inoculums effect' on the activity of a disinfectant (Maillard, 2005).

\section{CONCLUSION}

The evaluated disinfectant formula possesses promising antimicrobial activity so it can be used as a general disinfectant but not as a sporicidal agent. This finding indicates that this disinfectant could be used in complementary program with other products that has sporicidal activity against sporeforming bacteria. This study introduced a suitable guideline for the evaluation of disinfectants; which can be applied in healthcare facilities especially if it is using a combination of disinfectants.

\section{ACKNOWLEDGMENT}

The authors wish to thank Department of microbiological and quality control, Hikma Pharma Company, for supporting research work

\section{REFERENCES}

Ashour MS., Mansy MS., Eissa ME. 2011. Microbiological environmental monitoring in pharmaceutical facility. Egypt. Academic J. Biol. Sci. 3(1): 63-74.

Block SS. 1991. Disinfection, Sterilization, and Preservation, $4^{\text {th }}$ ed , Malvern, PA (ed), publisher: Lea and Febiger USA.

Clontz, L. 2008. Microbial Limit and Bioburden Tests: Validation Approaches and Global Requirements, $2^{\text {nd }}$ edition, publisher: CRC Press NY. 
Demple, B. 1991. Regulation of bacterial oxidative stress genes. Annu. Rev. Genet. 25: 315-337.

EC. 2003. Guide to Good Manufacturing Practice, Revision to Annex 1, European Commission, Brussels, 30 May 2003.

Eissa ME., Ashour MS., Mansy MS. 2012. Neutralizer evaluation study of some microbial isolates against two strong disinfectants with and without the presence of synthetic detergent. World Appl. Sci.J. 20 (6): 823-831.

Eissa MEA., Mahmoud AM. 2012. A novel improved bioburden recovery method using swabbing technique. Int. J. Microbiol. Rese. 3(3): 208-215.

Eissa ME., Ashour MS., Mansy MS. 2013. Impact of synthetic detergent on sporicidal activity in pharmaceutical facility. Egypt. Acad. J. Biol. Sci. 5(1): 4350.

Eissa ME., Ashour MS., Mansy MS. 2014. Study of antimicrobial power of amphoteric disinfectants of Tego series used in pharmaceutical industry. Egypt. Acad. J. Biol. Sci. 6(1):17-27.

EU. 2001. Qualifcation and validation, final version of Annex 15 to the EU, Guide to Good Manufacturing Practice, European Commission, Brussels, July 2001.

Favero MS. 2002. Products containing biocides: perceptions and realities. J. Appl. Microbiol. 92(S1): 72-77.

Foster, S.J. 1994. The role and regulation of cell wall structural dynamics during differentiation of endospore-forming bacteria. J. Appl. Bacteriol. Symp. Suppl. 76: 25S-39S.

Hiom, S.J.; Furr, J.R.; Russell, A.D. and Hann, A.C. 1996. The possible role of yeast cell walls in modifying cellular response to chlorhexidine diacetate. Cytobios. 86:123135.

Hiom SJ., Furr JR., Russell AD., Dickinson JR. 1992, Effects of chlorhexidine diacetate on Candida albicans, C. glabrata and Saccharomyces cerevisiae. J. Appl. Bacteriol. 72: 335-340.

Hugo, W.B. And Russell A.D. 1998. Chemical disinfectants, antiseptics and preservatives, in
Hugo and Russell's Pharmaceutical Microbiology, edited by Denyer, S.P., Hodges, N. And Gorman, S.P., 6th edition, Blackwell Science Ltd, United Kingdom, pp 201-228.

Jiminez L. 2004. Microorganisms in the Environment and their relevance to Pharmaceutical Processes, in Microbial Contamination Control in the Pharmaceutical Industry, edited by Jiminez, L., Marcel-Dekker, New York, pp 8-9.

Kramer A., Schwebke I., Kampf G. 2006. How long do nosocomial pathogens persist on inanimate surfaces? A systematic review. $B M C$ Infect. Dis.6:130-137.

Lateef A. 2004. The microbiology of a pharmaceutical effluent and its public health implications. World J. Microbiol. Biotechnol. 20(2): 167-171.

Maillard JY. 2005. Chapter 38. Testing the effectiveness of disinfectants and sanitisers, in Handbook of Hygiene control in the food industry, edited by Lelieveld, H.; Mostert, T. And Holah, J., Woodhead Publishing Limited and CRC Press LLC, Copyright (C) by Taylor \& Francis.

Maturin LJ., Peeler JT. 2011. Chapter 3. Aerobic Plate Count, in Bacteriological Analysis Manual, http://www.fda.gov/Food/Sd.ence Research Laboratory Methods Bacteriological Analytical Manual. htm.

Russell AD. 1991. Mechanisms of bacterial resistance to non-antibiotics: food additives and food and pharmaceutical preservatives. J. Appl. Bacteriol. 71:191201.

Russell AD., Furr JR. 1986. The effects of antiseptics, disinfectants and preservatives on smooth, rough and deep rough strains of Salmonella typhimurium. Int. J. Pharm. 34:115-123.

Russell AD., Russell NJ. 1995. Biocides: activity, action and resistance. Symp. Soc. Gen. Microbiol. 53: 327-365.

Shaker L.A., Russell AD., Furr JR. 1986. Aspects of the action of chlorhexidine on bacterial spores. Int. J. Pharm. 34: 5156.

Sutton SVW., Proud DW., Rachui S., Brannan DK. 2002. Validation of microbial 
recovery from disinfectants. PDA $J$. Pharmaceut. Sci. Technol. 56(5): 255-266.

Szybalski W., Bryson V. 1952. Genetic studies on microbial cross resistance to toxic agents. 1. Cross resistance of Escherichia coli to 15 antibiotics. J. Bacteriol. 64: 489499.

US Pharmacopoeia, <1072> 2014. Disinfectants and Antiseptics, United States Pharmacopeia, Baltimore, MD, USA.
US Pharmacopoeia, <1227> 1999. Validation of Microbial Recovery from Pharmacopoeial Articles. Pharmacopoeail Forum, 25 (1): 7574-7581.

Wu GF., Liu XH. 2007. Characterization of predominant bacteria isolates from clean rooms in a pharmaceutical production unit. J Zhejiang Univ. Sci. B. 8(9):666-672. 